Original Article

\title{
FABRICATION AND EVALUATION OF HERBAL TRANSDERMAL FLIM FROM HIBISCUS ROSA SINENSIS
}

\author{
S. DHANALAKSHMI ${ }^{*}$, N. HARIKRISHNAN ${ }^{2}$, M. DEVI ${ }^{3}$, V. KEERTHANA, VIJAYALAKSHMI \\ Department of Pharmacognosy ${ }^{1}$, Department of Pharmaceutical Chemistry and Analysis, ${ }^{2}$ Department of Pharmacology ${ }^{3}$, Faculty of \\ Pharmacy, Dr. M. G. R Educational and Research Institute, Velappanchavadi, Chennai 600077 \\ Email: dhanadinesh2011@gmail.com
}

Received: 12 May 2019, Revised and Accepted: 15 Jul 2019

\begin{abstract}
Objective: In this present study attempt was made to formulate transdermal patches contains phytoconstituents. The naturopathy does not involve any adverse effects.

Methods: Hibiscus rosasinensis aquous extracts was prepared. Transdermalpatches were prepared using drug with two different polymers. The prepared transdermal films were evaluated for their physiochemical characteristics such as physical appearance, weight uniformity, thickness, folding endurance; moisture content, surface $\mathrm{pH}$, Tensile strength. The in-vitro diffusion study was carried out using rat membrane. These parameters indicates the successful release of drug from the fabricated patch.
\end{abstract}

Results: With the overall observation it was concluded that the.

Conclusion: Fabrication of transdermal patch is successfully worked and subjected to diffusion study. Diffusion studies are carried out by using a fresh rat membrane. Phosphate buffer (6.6) is used as a solvent. Samples are collected for $24 \mathrm{~h}$ and absorbance is measured by using UV spectrophotometer at $226 \mathrm{~nm}$. It showed the successful release of drug from the fabricated patch.

Keywords: Hibiscus rosasinensis, Transdermal patch, Comparison

(C) 2019 The Authors. Published by Innovare Academic Sciences Pvt Ltd. This is an open-access article under the CC BY license (http://creativecommons.org/licenses/by/4.0/) DOI: http://dx.doi.org/10.22159/ijcpr.2019v11i5.35716

\section{INTRODUCTION}

The (TDDS) are defined as self-contained, discrete dosage forms which, when applied to the intact skin, deliver the drug (s), through the skin, at a controlled rate to the systemic circulation [1]. Transdermal drug delivery is a viable administration route for potent, low-molecular-weight therapeutic agents which cannot withstand the hostile environment of the gastrointestinal tract and/or subject to considerable first-pass metabolism by the liver. Transdermal drug delivery systems are topically administered medicaments in the form of patches that deliver drugs for systemic effects at a predetermined and controlled rate. A transdermal drug delivery device, which may be of active or passive design, is a device which provides an alternative route for administering medication. These devices allow for pharmaceuticals to be delivered across the skin barrier [2]. Nowadays, research into transdermal drug delivery has greatly increased over the past few years. One of the driving forces for this growth is the increasing number of drugs that can be delivered to the systemic circulation in clinically effective concentration via the skin portal. This has been possible because of the remarkable achievements of pharmaceutical technologists who have not only made the transdermal delivery system as the most successful non-oral systemic drug delivery system but also made its manufacture a highly successful commercial venture [3]

Hibiscus rosasinensis belonging to the family Malvaceaeis used as an important ingredient for preparing the transdermal patches due to its multiple therapeutic values. This shurb growing 1-3 meters, the Hibiscus rosa-sinensis flowers frequently in hot and humid conditions. Endemic to Southeast Asia, Hibiscus rosa-sinensis is grown ornamentally worldwide, and is one of the most common plants to use in laboratories for its flower.

The objectives of the present investigation is to fraction the leaf extract of $H$. rosa sinensis in ethanol and to screen the different fractions obtained on NOD mouse for antidiabetic activity.
The objectives of the present investigation Hibiscus rosasinensis extract have been found to be effective through advance techniques in pharmaceutical formulation.is to fraction the leaf extract of $\mathrm{H}$. rosa sinensis in ethanol and to screen the different fractions obtained on NOD mouse for antidiabetic activity.

Hence the present study is focussed to formulate the herbal transdermal flims and to screen their effectiveness in the transdermal delivery system using various parameters.

The objectives of the present investigation is to fraction the leaf extract of $\mathrm{H}$. rosa Sinensis in ethanol and to screen the different fractions obtained on NOD mouse for antidiabetic activity.

The objectives of the present investigation is to fraction the leaf extract of $\mathrm{H}$. rosa sinensis in ethanol and to screen the different fractions obtained on NOD mouse for antidiabetic activity.

he objectives of the present investigation is to fraction the leaf extract of $\mathrm{H}$. rosa sinensis in ethanol and to screen the different fractions obtained on NOD mouse for antidiabetic activity.

\section{MATERIALS AND METHODS}

\section{Materials used}

Hibiscus rosasinensis (Aqueous Extract) leaves were selected for the transdermal patch formulation. To this Potassium Dihydrogen Ortho phosphate, Sodium hydroxide, Anhydrous calcium carbonate, Ethanol LR, Chloroform LR, Carbopol-940/Pectin/Sodium alginate, Tween-80 were used for the transdermal formulation.

\section{Extraction of leaves of Hibiscus rosasinensis [4]}

The shade dried leaves were subjected to size reduction and passed in to sieve no20 and then 40 . About $500 \mathrm{~g}$ of the dried powder was extracted continuously in Soxhletapparatus with petroleum ether for $24 \mathrm{~h}$ to remove the waxy materials. Then it was extracted with distilled for $72 \mathrm{~h}$. After $72 \mathrm{~h}$, the water substance was evaporated to 
obtain the crude extract $(7.4 \% \mathrm{w} / \mathrm{v})$. The extract was dried under vacuum oven.

\section{Fabrication of transdermal patches of Hibiscus rosasinensis [5] Preparation of transdermal patch}

Three batches of Aqueous Extract of leaves of Hibiscus rosasinensis. Transdermal patches were prepared using drug with two different polymer in the ratio of $(1: 4)$.
Weighed quantity of polymer was dissolved in calculated quantity of water and heated on a water bath. The calculated amount of extract was added to the above mixture and stirred well until a homogenous mixture was formed. Then calculated amount of permeation enhancer and glycerin were added. In all the six batches the quantity of extract was same. The resultant mixture was poured into a Petri dish and air-dried at room temperature for $24 \mathrm{~h}$. The patches were then peeled off from the Petri dish with the help of a knife and kept in a desiccator.

Table 1: Formula for TDDS

\begin{tabular}{llll}
\hline S. No. & Formulation code & & Quantity \\
\cline { 2 - 4 } & TDDS-P & TDDS-S & TDDS-C \\
\hline 1. & Aqueous extract of Hibiscus rosasinensis & Aqueous extract of Hibiscus rosasinensis & $\begin{array}{l}\text { Aqueous extract of Hibiscus rosasinensis } \\
\text { Carbopol(mg) }\end{array}$ \\
2. & Pectin (m) & Sodium Alginate (mg) & Sodium hydroxide \\
3. & Sodium hydroxide & Sodium hydroxide & Anhydrous calcium carbonate \\
4. & Anhydrous calcium carbonate & Anhydrous calcium carbonate & Ethanol \\
5. & Ethanol & Ethanol & Chloroform \\
6. & Chloroform & Chloroform & Tween-80 \\
7. & Tween-80 & Tween-80 & Distilled water \\
8. & Distilled water & Distilled water & $2.5 \mathrm{ml}$ \\
\hline
\end{tabular}

\section{Preparation of calibration curve of aqueous extract of Hibiscus rosasinensis extract [6]}

Accurately weighed quantity (100 mg) of $\mathrm{AH}$ was transferred into a $100 \mathrm{ml}$ volumetric flask and dissolved in small amount of distilled water (D. W) and made up to the volume to make the standard stock solution of $1 \mathrm{mg} / \mathrm{ml}$. From the stock, $1 \mathrm{ml}$ was taken in $10 \mathrm{ml}$ volumetric flask and made up the volume with the buffer; from this solution $0.5 \mathrm{ml}$ to $3 \mathrm{ml}$ solution was transferred to $10 \mathrm{ml}$ volumetric flask and made up to required volume with more D. W and the resulting concentration ranges from 5 to $50 \mu \mathrm{g} / \mathrm{ml}$.

The absorbance of these solutions was determined at $382 \mathrm{~nm}$ using UV spectrophotometer. The calibration curve was constructed between the absorbance and concentration.

\section{Preparation of phosphate buffer $\mathrm{pH}$}

Phosphate buffer $\mathrm{pH} 7.4$ was prepared as per the method described in I. P 1996using disodium hydrogen phosphate and sodium hydroxide. The $\mathrm{pH}$ was adjusted to 7.4 prior to quantitative estimation [7].

\section{Physicochemical evaluation of Hibiscus rosasinensis transdermal patch [8]}

Formulated patches were subjected to the preliminary evaluation tests Formulated patches were subjected to the preliminary evaluation tests. Patches with any imperfections, entrapped air, or differing in thickness, weight (or) content uniformity were excluded from further studies.

\section{Uniformity of weight}

This was done by weighing five different patches of individual batch taking the uniform size at random and calculating the average weight of three. The tests were performed on patch which was dried at $60^{\circ} \mathrm{C}$ for $4 \mathrm{~h}$ prior to testing.

\section{The thickness of the patch}

The thickness of the patch was assessed by using digital vernier caliper at different points of the patch. From each formulation three randomly selected patches were used. The average value for the thickness of a single patch was determined.

\section{Drug content determination}

The patches were taken and added to a beaker containing $100 \mathrm{ml}$ of D. W. The medium was stirred magnetic bead for $5 \mathrm{~h}$. The solution was later filtered and analyzed for drug content with proper dilution at $382 \mathrm{~nm}$ spectrophotometrically.

\section{Folding endurance}

This was determined by repeatedly folding one patch at the same place till it broke. The number of times the patch could be folded at the same place without breaking gave the value of folding endurance.

\section{Percentage moisture uptake}

The patch was weighed accurately and placed in desiccators containing aluminum chloride. After $24 \mathrm{~h}$, the patch was taken out and weighed. The percentage moisture uptake was calculated as the difference between final and initial weight. With respect to initial weight. It is calculated by using following formula.

$$
\begin{aligned}
& \text { Percentage moisture content }=\frac{\text { Final weight }- \text { Initial weight }}{\text { Initial weight }} \times 100 \\
& \text { Percentage of moisture content }
\end{aligned}
$$

\section{Percentage of moisture content}

The patch was weighed and kept in desiccators containing calcium chloride. After $24 \mathrm{~h}$ the patch were taken out and weighed. The percentage of moisture content was calculated using the following formula.

Initial weight-Final weight

$$
\text { Percentage moisture content }=\frac{\text { Initial weight }- \text { Final weight }}{\text { Initial weight }} \times 100
$$

\section{Determination of surface $\mathrm{pH}[9]$}

The patches were allowed to swell by keeping them in contact with 1 $\mathrm{ml}$ of distilled water for $2 \mathrm{~h}$ at room temperature and $\mathrm{pH}$ was noted down by bringing the electrode in contact with the surface of the patch, allowing it to equilibrate for $1 \mathrm{~min}$.

\section{Percent elongation}

When stress is applied, a patch sample stretches and this was to as strain. Strain is basically the deformation of patch divided by original dimension of the sample. Generally elongation of patch increases as the plasticizer content increases. It is calculated by using following formula.

$$
\text { Percentage elongation }=\frac{\text { Increase in length of patch }}{\text { Initial length of patch }} \times 100
$$

\section{Tensile strength [10]}

Tensile strength is the maximum stress applied to a point at which the patch specimen breaks. It is calculated by the applied load at rupture divided by the cross-sectional area of the strip as given in the equation below 
Percentage elongation $=\frac{\text { Load at failure }}{\text { Patch thickness } \mathrm{x} \text { Patch width }} \times 100$

\section{Diffusion study [11]}

It was carried out using a fresh rat membrane tied to one end of an open cylinder, which act as a donor compartment. The film should be placed in such a way that it should be stuck on the mucous

\section{RESULTS}

Standard curve values of aqueous extract of Hibiscus rosasinensis membrane and the receptor compartment was filled with phosphate buffer have PH 6.6. The assembly was maintained at $37+5^{\circ} \mathrm{C}$ stirred magnetically. Samples of $5 \mathrm{ml}$ quantity were withdrawn at every two hours intervals up to $24 \mathrm{~h}$ from receptor compartment and replaced by equal volume of fresh solvent [12]. The withdrawn samples were analysed using uv-spectrophotometer at $226 \mathrm{~nm}$ using phosphate buffer have $\mathrm{p}^{\mathrm{H}} 6.6$ as blank.

Table 2: Standard values of aqueous extract of Hibiscus rosasinensis

\begin{tabular}{ll}
\hline Concentration $(\mu \mathbf{g} / \mathbf{m l})$ & Absorbance at $\mathbf{3 8 2} \mathbf{~ n m}$ \\
\cline { 2 - 2 } & Average \pm SD \\
\hline 0 & $0.000 \pm 0.000$ \\
10 & $0.091 \pm 0.001$ \\
20 & $0.182 \pm 0.001$ \\
30 & $0.273 \pm 0.001$ \\
40 & $0.363 \pm 0.001$ \\
50 & $0.432 \pm 0.001$ \\
60 & $0.512 \pm 0.008$ \\
Mean \pm SD: $\mathrm{n}=3$ & \\
\hline
\end{tabular}

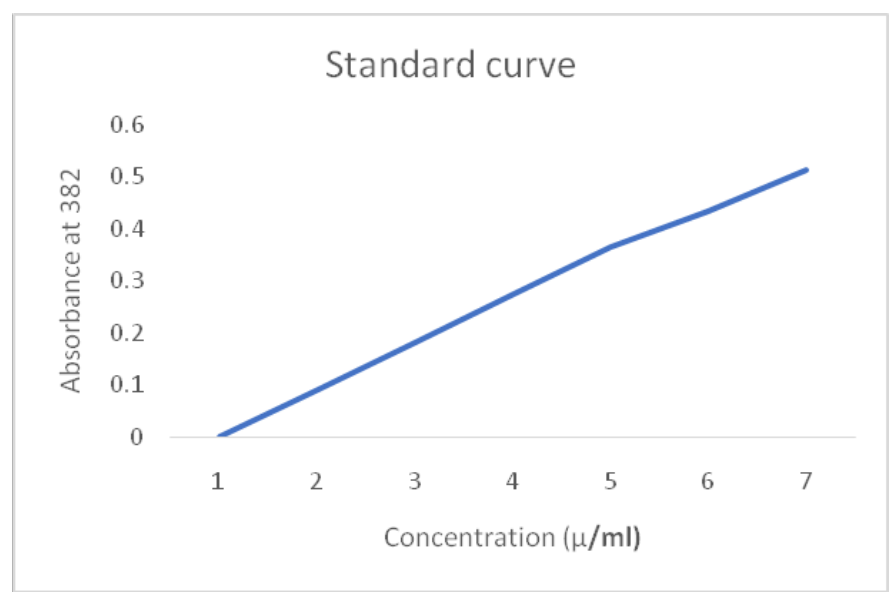

Fig. 1: Standard curve of aqueous extract of Hibiscus rosasinensis

Table 1: Physicochemical evaluation of aqueous extract of Hibiscus rosasinensis transdermal patches

\begin{tabular}{lll}
\hline Physico chemical parameter & Formulation code & Value \\
\hline Uniformity of weight (g) & TDDS-P (Pectin) & $0.46 \pm 0.85$ \\
& TDDS-S (Sodium alginate) & $0.41 \pm 0.65$ \\
Thickness (mm) & TDDS-C (Carbopol) & $0.49 \pm 0.23$ \\
& TDDS-P (Pectin) & $0.45 \pm 0.76$ \\
Drug content (\%) & TDDS-S (Sodium alginate) & $85.69 \pm 0.56$ \\
& TDDS-C (Carbopol) & $83.35 \pm 0.94$ \\
Folding Endurance e (no's) & TDDS-P (Pectin) & $249 \pm 0.23$ \\
& TDDS-S (Sodium alginate) & $265 \pm 0.44$ \\
Moisture Uptake (\%) & TDDS-C (Carbopol) & \\
& TDDS-P (Pectin) & $2.85 \pm 1.03$ \\
Moisture Content (\%) & TDDS-S (Sodium alginate) & $1.97 \pm 0.44$ \\
Surface pH & TDDS-C (Carbopol) & $3.422 \pm 0.22$ \\
& TDDS-P (Pectin) & $1.657 \pm 0.03$ \\
Percent Elongation (\% mm) & TDDS-S (Sodium alginate) & $7.3 \pm 0.72$ \\
\end{tabular}


TDDS-C (Carbopol)

TDDS-P (Pectin)

TDDS-S (Sodium alginate)

TDDS-C (Carbopol)
$6.361 \pm 0.87$

$6.253 \pm 0.62$

Table 2: In vitro drug diffusion study

\begin{tabular}{llll}
\hline Time in (min) & \% drug diffusion & & \\
\cline { 2 - 4 } & TDDS-P & TDDS-S & TDDS-C \\
\hline $1.00 \mathrm{pm}$ & 8.6 & 9.5 & 36.88 \\
$3.00 \mathrm{pm}$ & 15.96 & 16.28 & 47.18 \\
$5.00 \mathrm{pm}$ & 22.34 & 25.01 & 56.73 \\
$7.00 \mathrm{pm}$ & 31.23 & 36.43 & 61.83 \\
$9.00 \mathrm{pm}$ & 43.58 & 46.36 & 62.48 \\
$11.00 \mathrm{pm}$ & 55.25 & 55.34 & 64.40 \\
$1.00 \mathrm{am}$ & 65.46 & 64.22 & 68.85 \\
$3.00 \mathrm{am}$ & 73.04 & 71.46 & 82.88 \\
$5.00 \mathrm{am}$ & 79.06 & 77.56 & 87.98 \\
$7.00 \mathrm{am}$ & 81.98 & 79.32 & 90.53 \\
$9.00 \mathrm{am}$ & 85.17 & 81.98 & 90.53 \\
$11.00 \mathrm{am}$ & 89.26 & 84.65 & 93.08 \\
$12.00 \mathrm{am}$ & 93.81 & 89.87 & 98.05 \\
\hline
\end{tabular}

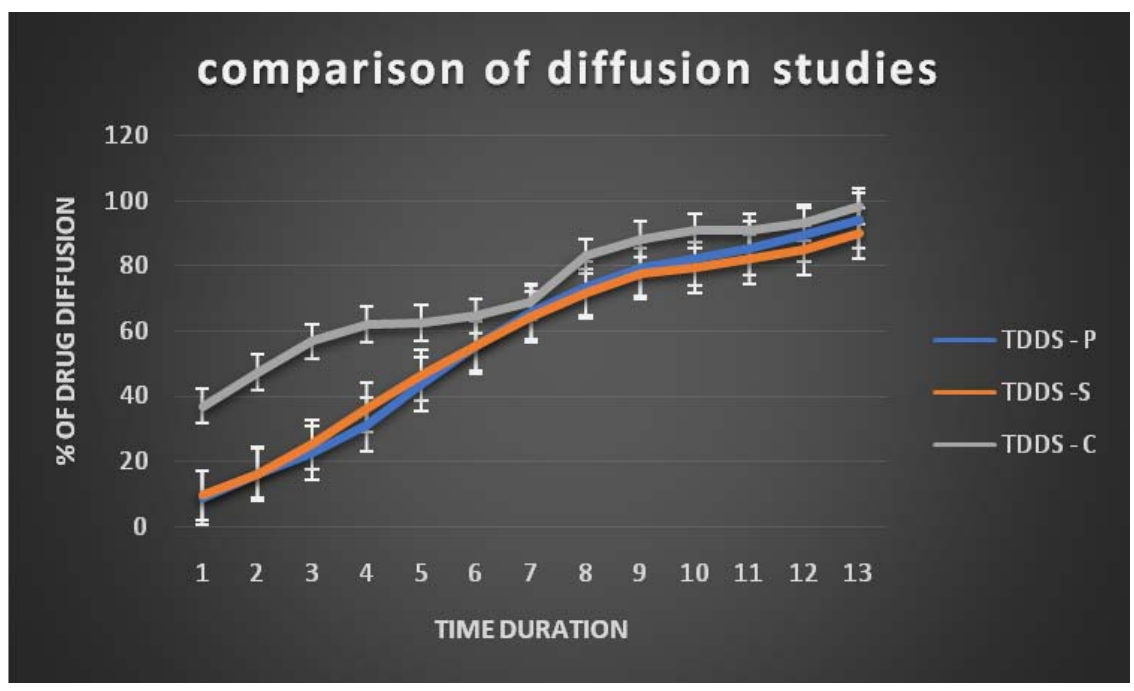

Fig. 2: Comparative studies of drug diffusion in TDDS formulations

\section{RESULTS AND CONCLUSION}

Ayurvedic systems of medicine have described specified methods and natural drugs. TDDS was ideally suited for drugs that undergoes hepatic first-pass metabolism with a short elimination half-life.

Transdermal patches are prepared by using Carbopol as a polymer, Carbopol are the synthetic product and used as gelling agent. Ethanol is used as both permeation enhancer and solvent. Its permeation enhancement is high in dilute ethanol when compared to concentrated ethanol. Tween -80 is also used as permeation enhancer.

Fabrication of transdermal patch is successfully worked and subjected to diffusion study. Diffusion studies are carried out by using fresh rat membrane. Phosphate buffer (6.6) is used as a solvent. Samples are collected for $24 \mathrm{~h}$ and absorbance is measured by using UV spectrophotometer at $226 \mathrm{~nm}$ [13].

The result of diffusion studies has been discussed in a graph by plotting time in $\mathrm{x}$-axis and cumulative \% release in y-axis. The plot showing gradual increase in cumulative \% release, it indicates the successful release of drug from the fabricated patch. So, the fabricated patch should be best one. Through the present experimentation, it has been found that the drugs of ayurvedic origin can be utilized in a better form with enhanced efficacy for incorporation in modern dosage form. This work is one of the first few attempts to utilize ayurvedic drugs through TDDS [14].

As an extension of this work, pharmacokinetic studies, in vivostudies on higher animals and clinical research on human beings and stability studies can be carried out in future.

\section{AUTHORS CONTRIBUTIONS}

All the author have contributed equally

\section{CONFLICT OF INTERESTS}

Declare none

\section{REFERENCES}

1. Munden BJ, Dekay HG, Banker GS. Evaluation of polymeric materials screening of film coating agents. J Pharm Sci 1964;53:395-401.

2. Bodmeier $\mathrm{R}$, Paeratakul $\mathrm{O}$. Leaching of water-soluble plasticizers from polymeric films prepared from aqueous colloidal polymer dispersions. Drug Delivery Int J Pharm Sci 1992;18:1865-82. 
3. Sayan Bhattacharjee, S Nagalakshmi, S Shanmuganathan. Formulation characterization and in vitro diffusion studies of herbal extract loaded mucoadhesive buccal patches. Indian J Pharm Sci Res 2014;5:4965-75.

4. Itelima JU, Nwokedi VC, Ogbonna AI, Nyam MA. Phytochemical screening and antimicrobial activity evaluation of aqueous and ethanolic extracts of the leaf of azadirachta indica juss (Neem) on some. Microorganisms 2016;3:56-60.

5. Mariana C Galean, Carlos HG Martins, Jaqueline Massuco, Taís M Bauab, Luis VS Sacramento. Phytochemical screening of Azadirachta Indica a juss for. Antimicrobial Activity 2017;11:117-22.

6. Satyabrata Bhanja, BrijMohan Singh, Rawat Muvvala, Sudhakar Bibhuti, Bhusan Panigrahi. Design, development and evaluation of transdermal patches of ramipril. Int J Pharm Sci Res 2014;3:350.

7. Wahid A, Sridhar BK, Shivakumar S. Preparation and evaluation of transdermal drug delivery system of etoricoxib using modified chitosan. Indian J Pharm Sci 2008;70:55-60.

8. Suneetha Cherukuri, Uma Rajeswari Batchu, Kiranmai Mandava, Vidhyullatha Cherukuri. Formulation and evaluation of transdermal drug delivery of topiramate. Int J Pharm Investigation 2017;7:1-8.

9. Mukherge B. Design development physicochemical and in-vitro evaluation of transdermal patches containing diclofenac diethyl ammonium salt. J Pharm Sci 2002;91:2076-89.

10. Das K, Dang R, Bhaskaran S, Roopashree TS. Recent advances in medicinal plants in diabetes treatment. Recent progress in medicinal plants. Phytopharmacol Ther 2008;19:150-91.

11. Heard CM, Johnson S, Moss G, Thomas CP. In vitro transdermal delivery of caffeine, theobromine, theophylline, and catechin from an extract of Guarana, Paulliniacupana. Int J Pharm 2006;317:26-31.

12. Rao BK, Kesavulu MM, Apparao Ch. Antihyperglycemic activity of Momordica cymbalaria in alloxan diabetic rats.J Ethanopharmacol 2001;78:67-71.

13. Bhalla HL, Bhate AS. Feasibility studies on transdermal films of ephedrine. Indian Drugs 1994;31:328-32.

14. Ahad HA, Chitta SK, Anil KB, Amarnath RB, Chandrashekar AV, Gangadhar. Permeation studies of diclofenac sodium from ficuscarica fruit mucilage matrices for transdermal delivery. Int J Pharm Tech Res 2010;2:1013-7. 